p 53-57. In: Hare, M.D.; Brock, J.L., editors. Producing Herbage Seeds.

Grassland Research and Practice Series No. 2,

New Zealand Grassland Association, Palmerston North.

\title{
HEAT DAMAGE AND DRYING EFFECTS ON SEED QUALITY
}

\author{
M.J. Hill and C.R. Johnstone \\ Seed Technology Centre, Massey University
}

\begin{abstract}
Heat damage to seed can occur as a result of the cumulative effects of respiration and fungal heating, and by the accumulation and retention of radiant heat within the seed mass following harvest - both situations being collectively referred to as 'field heating'. Another type of heating damage occurs in heated air drying systems. Excessive drying air temperature can have deleterious effects on seed quality - this is generally referred to as "drying damage".

Both 'field heating' and 'drying damage' result in loss of quality due to the thermosensitivity of seeds. This is characteristic which is markedly influenced by the seed moisture content, by the extent and duration of heat production, and by the retention of heat within the seed mass.

The role of the thermophilic fungi, Aspergillus spp., in accentuating heat damage, and the effects of both 'field heat' and 'drying damage' on the market acceptability and quality of seed is also discussed.
\end{abstract}

Keywords: Respiration heating, fungal heating, Aspergillus, seed quality

\section{INTRODUCTION}

The moisture content of seed has a strong bearing on its keeping quality and its longevity in storage. In addition it causes heat and water production as a result of respiration; influences the levels of seed vigour and germination; affects the amount of damage caused during threshing, drying, and processing and has a strong effect on the development of storage moulds and insect activity. (Hill, 1982).

All seed producers who have harvested seed 'out of condition' are aware of the problem of seed heating causing germination damage. In the past, seed quality losses were often so high that growers soon learnt to take remedial action.

e.g. seed was left in sacks in the field to cool

sacks were open stacked to allow air movement around the seed

sacks were loose stacked on the grating in the wool shed

sacks were half filled and hung over a fence to cool and 'condition' for some weeks seed, if it became to hot, was tipped out onto a floor and turned reguiarly to dissipate heat.

These types of time consuming and laborious systems soon lead to an increasing interest in the development and use of artificial drying systems whether these were located in commercial seed stores or as on farm driers. (Crosbie, 1972).

\section{CAUSES OF HEAT DAMAGE}

The 'heating' process in seed, with subsequent damage to germination is well known. However, jts cause and mode of attack is not. Heat damage can be caused by three particular circumstances:

\section{Field heating in wet seed}

When 'out of condition' seed is harvested it is generally dry on the outside but has a wetter interior. In only a few hours this moisture difference starts to even out resulting in the seedcoat 'damping back'. The seed becomes 'sticky' and loses its flow characteristic. This change in a seed lot is referred to as "going through a sweat" or "wetting back". At the same time the humidity of the inter-seed spaces increases greatly. This situation creates an ideal environment for heat production by a range of micro-organisms already present on and in the seed. These micro-organisms, principally fungi of the Aspergillus and Penicillium groups, produce heat and water as a by-product of their metabolism. Both products reinforce the problem. In the now warmer and moister environment the fungi multiply faster, produce more heat and ultimately raise the temperature of the seed to a point where seed quality damage occurs. This process can take as little as $12 \cdot 15$ hours (Hill, 1975).

The particular species of Aspergillus involved in this heating process include $A$. glaucus (Matthews and Hill, 1967), $A$. amstelodumi (Kulik, 1969) and A. restrictus, $A$. 
flaws, A. candidus, A. ochraceus and A. repens (Christensen, 1973).

The development of storage fungi in moist seedlots can be deceiving, particularly as it is preceded by a respiration heating phase of approximately 24 - 36 hours duration and a lag phase which may continue for a further $24 \cdot 28$ hours. This lag phase, in particular, can mislead farmers into thinking seed has stopped heating. Often, however,- the lag phase is followed by an intense and rapid microfloral heating phase which can raise seed temperatures up to $55^{\circ} \mathrm{C}$ (Hill, 1975). This is when the damage to seed germination occurs.

Heat damage in herbage seeds is reflected in lower germination. Even though the germination capacity of the seed may still be very high immediately after it is damaged, the first sign of deterioration is usually seen within a few weeks. This shows' up initially as a lowered interim germination count, followed by an increase in abnormal seedling percentage and is finally reflected in a high percentage of dead seed (Figure 1). The rate of deterioration in seed quality increases with increasing heat, with increasing time of exposure of seed to high temperatures, and is greatest in lines of seed which have heated at high moisture contents.

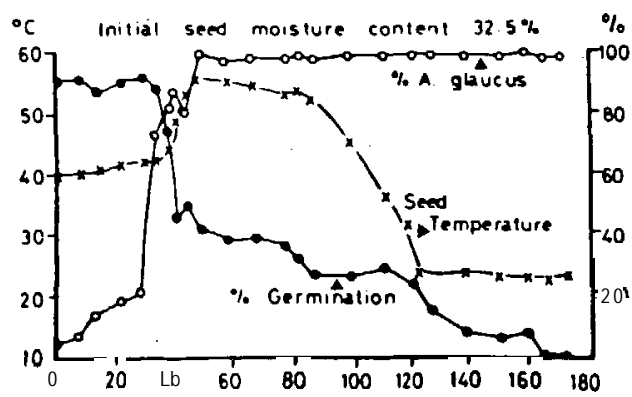

The worst combination is to subject a very damp line of seed to high heat for a long time (Hill, 1975).

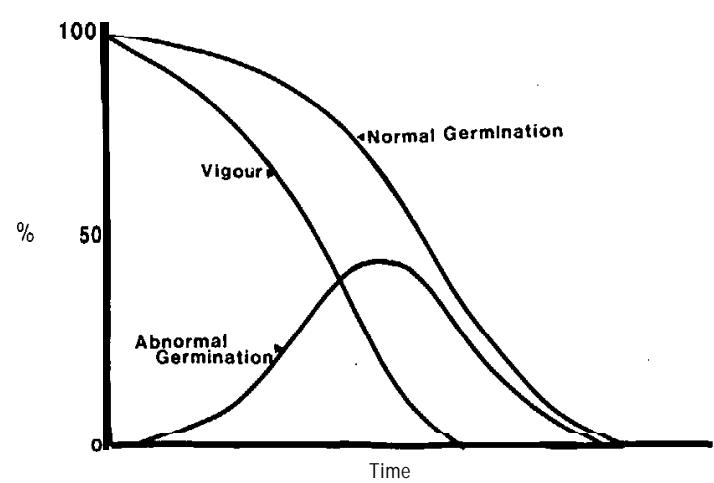

FIGURE 1. Changes in seed viability components with time.

\section{Field heating in dry seed}

The 'heating' of wet seed is easy to understand. However, the accumulation of heat in seedlines which have been harvested at a 'safe' and relatively dry moisture level is more confusing. Nevertheless many cases of 'heat damage' in dry seed have been observed. The reason is that
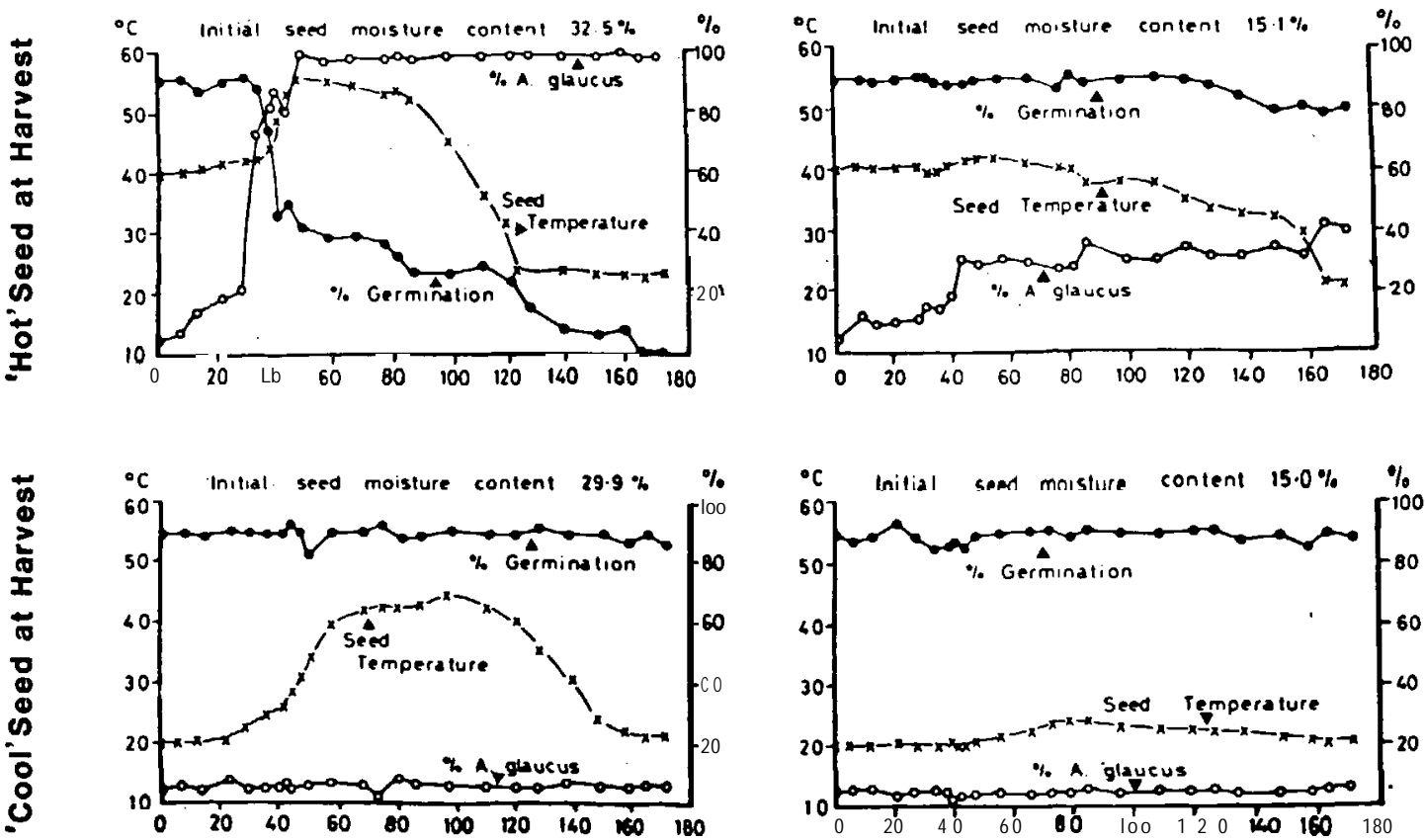

'Wet'Seed at Harvest

FIGURE 2. Changes in germination microflora and temperature of seed harvested at different moisture contents and seed temperatures (Hill, 1975). 
seed threshed from the windrow on a hot, sunny day will invariably contain radiant heat from the sun which gives it a temperature up to $10-12^{\circ} \mathrm{C}$ higher than ambient air temperature. This effect is greatest on hot, clear days, is reduced by cloud, and ceases at sunset. (Hill and Crosbie, 1966).

In situations where hot seed is stored in bulk, seed heating occurs. The same seed stored in bags generally does not heat. The main reason is that any particular seed in a sack is not more than approximately $10-12 \mathrm{~cm}$ from the outside and heat loss into the surrounding air occurs quite rapidly. Seed in bulk, however, may be 2-3 metres or more from the outside. This fact, coupled with the well known insulating property of seed results in heat retention in the mass and subsequent seed damage.

The storage of seed at an initially high temperature, (whether this occurs as a result of the respiration heating of wet seed or the retention of radiant heat in freshly harvested seed) even though it may be at a moisture content considered safe for storage, can be dangerous in allowing the buildup of Aspergillus glaucus in the seed to a stage where the fungus continues heat production in the mass. Aspergillus glaucus plays an important role in raising the temperature of stored seed from $3540^{\circ} \mathrm{C}$ (a level induced by seed respiration processes, by radiant heat retention and possibly by the activity of mesophilic moulds such as Rhizopus spp.) to $50-55^{\circ} \mathrm{C}$ or more. (Figure 2) (Matthews and Hill, 1967, Hill 1975). Such conditions result in the development of a succession of progressively thermophilic species of Aspergillus from the 'pioneer' species A. glaucus, and A. restrictus to the species which only appear during the later stages of deterioration e.g.A . niger and A. flavus (Figure 3) (Christensen, 1973).

Assessments of the-level of Aspergillus in seed samples plated onto high salt agar can be used to detect heat damage and consequently potential deterioration in a wide range of seed crops. The detection of high levels of storage fungi in herbage seeds is a guarantee that at some stage the seed has been exposed to hot and possibly moist conditions and is consequently of potentially poor quality (Hill and Johnstone, 1984).

Aspergillus development can be controlled in hot seed by removing the heat. This is generally accomplished by blowing cool night

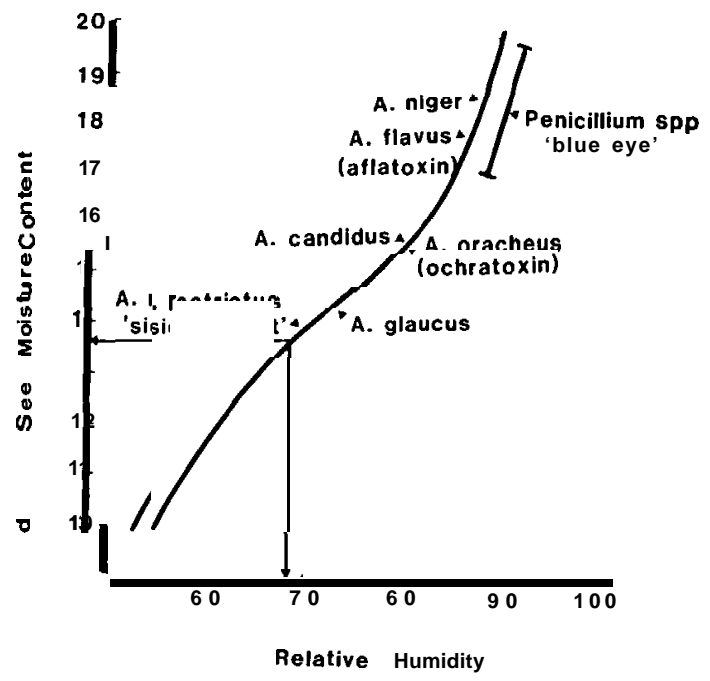

FIGURE 3. Ecological succession of Aspergillus storage fungi at different levels of seed moisture content and relative humidity in wheat (after Christensen, 1973).

air through the seedlot. The aim should be to cool the seed to within $1-2^{\circ} \mathrm{C}$ of ambient air temperature quite quickly. (Crosbie, 1972).

Some farmers are reluctant to use cold night air for cooling seed because of its high humidity and the fear of 'wetting back' seed which was already dry. This risk is small compared with the risk of storing 'hot' seed. The reason is that the fan does not run for long enough to pass sufficient air through the mass to add much water to the seed. Any moisture which is added only affects the seed nearest the air intake.

\section{Artificial drying}

It is well known that seeds are heat sensitive and that heating to a definite temperature will reduce germination. High temperatures in drying moist seed are particularly injurious. In such cases free surface moisture is removed quickly, and this rapid evaporation removes heat from the seeds fast enough to keep the actual seed temperature depressed. As the moisture of the seed drops, however, the supply of moisture for evaporation is less readily available and actual seed temperature will increase. Under these conditions, seed injury can occur.

In farm practice wet seed is normally dried within a few hours of being harvested. In some cases the moisture will be high because the seed has not reached harvest ripeness; in other cases 
seed will be mature but wetted by atmospheric conditions.

The artificial drying of herbage seed crops offers advantages by permitting:-

-early harvest which reduces field losses of seed from weathering and natural shattering.

-planning of the harvest season to make better use of labour.

Seed crops can be harvested when natural drying conditions are unfavourable.

-the maintenance of seed viability. By removing moisture the possibility of seed 'heating' with a subsequent reduction or destruction of germination is decreased.

-extended seed storage life. This is often important when large amounts of seed are being stored and carried over from one season to the next.

-the sale of a better quality product. (Crosbie, 1972).

Artificial drying of seed is simply a way of accelerating the rate of natural movement (diffusion) of water from the inside of the seed to the surface where it is available for removal by evaporation into the air. Diffusion rate depends on seed size and composition, speed of surface evaporation, temperature, initial moisture level, seed coat permeability and time. Evaporation rate is a function of the humidity and temperature of the surrounding air and air flow rate. (Hill, 1982).

No single temperature can be quoted beyond which it is unsafe to heat seed during drying, because many factors are involved. These include the type of seed, maximum heat tolerance, seed moisture content, duration of temperature rise, rate of drying and the purpose for which seed is to be used.

If the temperature sensitivity of a particular type of seed is not known, it is wise to select the drying temperature according to the moisture level of the seed. The figures in

TABLE 1 Maximum safe drying temperature without germination loss at different levels of seed moisture content.

\begin{tabular}{ll}
\hline Moisture \% & ${ }^{\circ} \mathrm{C}$ \\
\hline above 20 & 32 \\
$18-20$ & 34 \\
$14-17$ & 37 \\
$11-13$ & 40 \\
$9-10 \quad$, & 42 \\
Below 10 & 43 \\
\hline
\end{tabular}

Table 1 are safe for most seeds, including ryegrass, cocksfoot, timothy, clovers and peas. (Hill and Crosbie, 1966).

In continuous flow driers with seed at 15 to $20 \%$ moisture content, and seed being dried at approximately 30 minutes per pass, ryegrass seed. can tolerate a drier temperature of up to $46^{\circ} \mathrm{C}$ with no detrimental effect on germination, but an operating temperature of $43{ }^{\circ} \mathrm{C}$ is recommended.

In cases where bulk harvested ryegrass seed is passed over a drier very quickly - for example 20 minutes per pass - the internal seed moisture often does not have time to migrate to the seed surface for evaporation. In such cases, seed which may appear dry on the surface may heat in storage because of internal seed moisture migrating to the seed surface and causing sweating and mould growth. It is because of this low external and high internal seed moisture that moisture meters using whole seeds can give moisture levels lower than the true level. It is thus necessary to use ground seed samples in meters for accurate moisture determinations.

Short drying periods tend to combat moulds and germination injury, but drying too fast also has its danger. During rapid drying the coat of some seeds shrink or split and may become impermeable to moisture, even though inner parts of the seed remain wet. This latter condition, called case-hardening, can prevent complete drying and may increase the percentage of hard seeds in some seed types, e.g. white clover. (Hill, unpub. data).

Market acceptability of heat damaged seed is often low - resulting in a downpricing due to both appearance and quality. In particular the following characters can be the basis of buyer discrimination in herbage seeds - scorching, discolouration, mould activity, cracking (external and internal), increase in abnormal seedlings, case hardening and reduced germination.

The production of high quality seed sounds easy. However, the preservation of seed quality generally, and of high germination capacity in particular, is one of the least recognised and understood aspects of seed production. There is no doubt that a clearer understanding of the causes and control of 'field heating' or heat damage during drying would greatly improve the quality of herbage seed produced in New Zealand. This is particularly the case in years when 
unfavourable climatic conditions force seed producers to harvest much of the national herbage seed crop 'out of condition'.

\section{REFERENCES}

Christensen, C.M. 1973. Seed Science and Technology 1: 547-562.

Crosbie, C.J. 1972. Heat damage and small seeds. Advisory Services Division, M.A.F. Christchurch

Hill, M.J. 1975. Australian Seed Science Newsletter I: $43-52$.
Hill, M.J. 1982. In: Hor Yue Luan, editor. Proceedings 3rd Regional Seed Technology Workshop for ASEAN and the Pacific.

Hill, M.J.; Crosbie, C.J. 1966. New Zealand Journal of Agriculture 112(1) 48-53.

Hill, M.J.; Johnstone, C.R. 1984. Proceedings of the New Zealand Grassland Association 45: 243-246.

Kulik, M.M. 1969. Seed Pathology Research. p4. In 'Search' Publication of the American Seed Research Foundation.

Matthews, B.D.; Hill, M.J. 1967. New Zealand Journal of Agriculture 114(2): 25-27.

\section{DISCUSSION}

Q. How widespread is heat damage in herbage seeds?

A. One recent survey indicated that nearly $50 \%$ of seedlots with germinations of $<80 \%$ had poor germination because of heating damage.

Q. Is there any relationship between time of cutting, seed immaturity and heat damage?

A. Irrespective of the reason for high moisture level in seeds, heat is produced as soon as wet seed is placed in a mass and damage can occur before the farmer can detect it.

Q. Do variations in temperature and relative humidity affect seed drying?

A. Yes. Wet seed is much more prone to damage at higher temperatures, so temperature level must be kept low during the early stages of drying, which are the most critical for seed damage.

Q. Do you recommend greater use of cooled air immediately after harvest for seed drying?

A. Yes, this is a good practice. Increasing the ambient air temperature by only $5{ }^{\circ} \mathrm{C}$ makes air more suitable for drying seedlots. This can be done by using the waste heat from a tractor.

Q. If a moist seedlot $(20 \%)$ is kept cool $\left(15^{\circ} \mathrm{C}\right)$, will fungal damage still occur?

A. Cooling prevents fungal development, so no damage would occur. 